\title{
A Literature Review on Structural Reform of Agricultural Supply Side
}

\author{
Fenlan Mao, a, Weiwei Guo ${ }^{1, b}$ \\ ${ }^{1}$ College of Economy and Management, Longdong University, Qingyang, Ganshu, 745000 \\ ${ }^{a}$ email, ${ }^{b}$ email
}

Keywords: Agricultural Supply Side, Agricultural Supply Side Structural Reform, Literature Review

\begin{abstract}
The structural reform of the agricultural supply side is the major deployment of the "No. 1 document" on agriculture, not only for the direction of agricultural industry development, but also for the agricultural industry structure optimization adjustment to play a needle "tonic", also engaged in agricultural economic research experts and scholars Correct future and long-term research direction to play a "heading" role. This paper summarizes the policy of "structural reform of agricultural supply side", which is related to the optimization and upgrading of agricultural industry structure, the cultivation of agricultural enterprises, the integration of agriculture, the development strategy of agricultural brand, the innovation of agricultural technology, "Rural land management system reform", "agricultural development policy" and other research results.
\end{abstract}

\section{Introduction}

The Central Committee of the Communist Party of China and the State Council issued the "No. 1 document" for three consecutive years, focusing on the development of agriculture, agriculture, agriculture, agriculture, agriculture, agriculture, agriculture, agriculture, agriculture, agriculture, agriculture and industry The main contradiction of agricultural development is the main contradiction in the form of "No. 1 document". It is concluded that the main contradiction of agricultural development is transformed from structural deficit to structural contradiction, and the supply of supply is insufficient and the supply is insufficient. "Agricultural supply side of the structural reform" attaches great importance. Based on this, in 2016 throughout the country began to address the contradiction between supply and demand of grain varieties, take the initiative to optimize the agricultural production structure and regional layout, although the total grain output in 2016 than in 2015 to reduce 520.1 million tons, the end of the trend of 13 consecutive times, the first time Decline, but from the international competitiveness of agricultural products to enhance the quality of agricultural development, optimize the industrial structure and other long-term development goals, 2016 is thirteen years for the first time to implement a meaningful attempt to reduce production efficiency. 2017 "No. 1 document" pointed out that the current imbalance between supply and demand of agricultural products, unreasonable allocation of resources, resource and environment pressure, farmers continue to grow income and other issues is still very prominent, increase production and improve quality, rising costs and low prices, high inventory And poor sales, small production and large market, domestic and foreign prices upside down and other contradictions need to crack. We must follow the new situation and new requirements, adhere to the problem-oriented, adjust the focus of work, and further promote the structural reform of agricultural supply side, accelerate the development of agricultural and rural development of new kinetic energy, to ensure national food security on the basis of tightly around the market demand changes to increase Farmers' income, effective supply and protection as the main objective to improve the quality of agricultural supply as the main direction to institutional reform and mechanism innovation as a fundamental way to optimize the agricultural industry system, production system, operating system, improve land production rate, resource utilization, Labor productivity, and promote agricultural and rural development by the excessive dependence on resource consumption, the main demand to meet the demand, to the pursuit of green ecological sustainability, pay more attention to meet the quality of demand changes. The document not only for the direction of the development of agricultural industry, agricultural industry structural adjustment for the adjustment of a shot "tonic", but also for agricultural economic research experts and scholars in the future and 
long-term research direction to play a "heading" role. CNKI literature data show that 2016,2017 two years, the "agricultural supply side reform" as the research topic of the literature as many as 4,000 articles, including but not limited to "agricultural industry structure optimization and upgrading", "agricultural management main body cultivation "Agricultural industry development strategy", "agricultural technology innovation", "rural land management system reform", "agricultural development policy", the agricultural supply side structural reform has become the agricultural economy research "compass" The

\section{The Agricultural Industry Structure Optimization and Upgrading}

Li Guoxiang that from the agricultural side of the supply side to solve China's agricultural development problems, the key is the structural adjustment, the way to change and deepen the reform. The new economic situation and the international competitive environment require the new agricultural management and other agriculture-related entities to be able to focus on the agricultural supply side of the structural reform and innovation, change the habit of practice, co-ordinate the international and domestic markets and foreign two domestic resources, To overcome the competitive advantage of China's agricultural cost competition to promote China's agricultural transformation and upgrading. Li Shipeng analyzed the agricultural data in Xinjiang after 1985, and analyzed the structural similarity, information entropy and production efficiency. The results showed that Xinjiang's agricultural industry structure was unstable and the proportion of agricultural industry structure was very different, and the production structure was too single. Xinjiang Agricultural industry structure is not harmonious, Xinjiang agricultural industry structure and Xinjiang national economy, farmers' income, people's employment development of the uncoordinated; Xinjiang agricultural industry structure is low efficiency, agricultural production costs and transaction costs are higher, mechanization and scientific and technological content is not high. Based on the characteristics of these problems, the idea of optimizing the adjustment of crop and animal husbandry structure is set up. The redistribution plan of land resources and the development direction of animal husbandry in Xinjiang are designed, and the problem of planting industry is the high efficiency of water resources The use of the problem, water-saving agricultural output and output should be better than normal water agriculture; animal husbandry should pay attention to economies of scale, increase technical support and scientific and technological achievements, give priority to the development of dairy industry, followed by beef cattle and sheep breeding, Eggs and poultry breeding; forestry to economic forest-based, fishery to Xinjiang's unique species for the breeding direction.

\section{The Main Agricultural Management}

Yang Lei, etc. will focus on the structural reform of the rural financial supply side to serve the main body of rural scale management, claiming that the financial structure should be from the credit scale, credit period, credit products, financial services and other aspects of reform, to meet the financial needs of agricultural enterprises, Diversification, multi-level, service characteristics. Sichuan University Pan Kun defines farmers as the main contributors and the main beneficiaries of the structural reform of the agricultural supply side. The structural reform of the agricultural supply side must accelerate the cultivation of new professional farmers through the run of agricultural vocational education and carry out the new agricultural management main leaders Cultivating the action and optimizing the use of funds and policy support for the cultivation of professional farmers, and highlighting the labor force of the peasants in the structural reform of the agricultural supply side. The author analyzes the influence of farmers' subjectivity on market consciousness, land rights, educational and cultural conditions and political status, which seriously hinders the smooth and effective promotion of structural reform of agricultural supply side. It is necessary to strengthen the rural credit loan system and optimize the financing environment, and to support a group of farmers and entrepreneurs to build the market economy of the farmers; through the extensive development of rural grassroots consultation and democracy, To protect the agricultural management system in 
the process of innovation in the right to farmers to build the political subjectivity of farmers; through the full implementation of rural nine-year compulsory education, establish and improve the vocational training system for farmers, attention to the whole process of multi-dimensional vocational skills guidance, Vigorously promote the construction of rural cultural system and other measures to consolidate the conditions of rural culture and education, cultivate a new type of professional farmers, farmers to build the cultural subjectivity.

\section{The Development of Industrial Integration}

Agriculture and the second and third industry integration development is the expansion and upgrading of agricultural industrialization. Li Junling explored the impact of industrial integration on the multi-functional agriculture, that ecological agriculture to strengthen the ecological environment protection function of agriculture, tourism agriculture to expand the cultural function of agriculture, biomass agriculture to extend the economic and ecological functions of agriculture. Zhang Yibo stressed that through the integration of agriculture and other industries can achieve agricultural modernization and narrow urban and rural income gap. Zhang Shoukui enumerated the success stories of Dali County in Shaanxi Province and Jinshan District of Shanghai, and believed that the integration of rural industrial development in the first half of the year was the scientific choice of structural reform of agricultural supply side. The key point of the integration of the three production is to improve the efficiency of agriculture, to activate the agricultural polymorphism, plea and broaden the agricultural function. The policy focus is on establishing the linkage mechanism between the industrial chain and the peasants, highlighting the peasants' The goal is to promote the modernization of agriculture, promote industrial agglomeration and factor concentration, give full play to the unique advantages of rural areas, tap the various functions of agriculture in depth, cultivate and expand the new industry of rural new industry, build rural industrial system, promote new Urbanization, urban and rural development integration. At the same time pointed out that to promote the integration of rural industry development should rely on agricultural resources to integrate market elements, pay attention to "production, city, people" interactive integration, leveraging financial policy support, adhere to market demand. Wang Xingguo proposed that China's agricultural bear the cost of the floor rising, the price ceilings continue to press the double squeeze, faced with agricultural production and price subsidies "yellow line" began to approach and resource environment "red light" began to light up the double constraints, while With the continuous growth of urban and rural incomes driven by the upgrading of consumption structure, promote rural integration of rural industry is to cope with the new reality of the rural economy a real choice. Urban and rural residents to upgrade the structure of consumption, in the rural areas of industrial supply side of the structural reform issued a strong signal at the same time, but also for the integration of rural economic development to create the conditions. To seize the new opportunities for rural development, promote the integration of rural industrial development, need to co-ordinate the use of rural natural, ecological and cultural resources, and further enhance the agricultural products processing industry, and constantly strengthen the construction of rural ecological civilization, in-depth explore a variety of agricultural functions, Rural industry links and resource elements of the integration of interaction, increasing the supply of ecological and cultural products to meet the growing urban and rural residents of diversified, personalized consumer demand.

\section{The agricultural brand strategy research}

Chen Wensheng that to achieve the strategic transformation of agricultural development, promote the agricultural supply side of the structural reform, the key is to change the mode of agricultural management, agricultural products from the scale of production to the regional brand management of agricultural products to change, to support regional landmark agricultural products brand. Zhejiang University, China Agricultural Brand Research Center Director Hu Xiaoyun pointed out that the low value of the consumer era has become history, to diversify consumption, personality 
consumption, symbolic consumption for the characteristics of consumer demand is the trend of the times, the article from five aspects of agricultural reform The focus should be on the deep implementation of the Chinese agricultural brand strategy. The agricultural brand strategy is the strategy of agricultural modernization, but also the development of the whole society, and the agricultural brand strategy is the strategy of agricultural modernization. The agricultural brand strategy is the strategy of agricultural modernization, The agricultural brand strategy is not only the agricultural product strategy, but also the agricultural value reengineering and promotion strategy. The agricultural brand strategy is not only the agricultural product supply strategy adjustment, but also the agricultural value reengineering and the promotion strategy. $\mathrm{Li} \mathrm{Yan,} \mathrm{etc.} \mathrm{Based} \mathrm{on} \mathrm{the}$ perspective of the county government, put forward the agricultural brand to lead, to "one county one product" as the starting point to implement the agricultural supply side of the structural reform of the meaning, objectives and ideas, put forward from the innovative brand of agricultural organization management, Innovation and quality and safety protection model, innovative agricultural products circulation mode 3 dimensions, from the "establishment of industrial organizations, build joint brands, to achieve regional common brand", "the introduction of third-party services, social co-governance, to achieve quality and safety" Associated Press, to strengthen the production and marketing docking, to achieve the role of radiation "three aspects to promote the" one county a product "the basic strategy of development and implementation path.

\section{Agricultural Technology Innovation Research}

From the technical innovation aspects of the agricultural supply side of the structural reform of the existing literature is relatively small, the quality is not very high. In order to solve the existing problems in the aspects of production planning, facilities and equipment, operation main body and product circulation, this paper puts forward the facilities of institutional innovation, technological innovation and structural adjustment. Guan Huiming that the existing quantitative, yield-based technical system for quality, commodity-oriented supply side of the lack of support, agricultural technical services can not be limited to a production, but also should penetrate the quality of agricultural products, standards and two Industry processing areas, advocated the establishment of a new technical system to adapt to the structural side of the structural adjustment.

\section{The Study of Rural Land Management System Reform}

Renmin University of China Kong Xiangzhi reform of the land system as the first focus of the structural reform of the agricultural supply side is to achieve the agricultural field to produce capacity, reduce costs, make up short board, to achieve the adjustment of agricultural management structure, the formation of efficient new agricultural management The main body and the new agricultural social service system foundation. It is suggested that deepening the reform of rural land system can further stimulate the enthusiasm of the farmers in agricultural production and management, and avoid the land predatory operation. It can promote the circulation of rural land, cultivate the new management subject of agriculture, develop the appropriate scale of agriculture management, protect the farmers' land property rights and interests So that they can be relieved to engage in agricultural production and management or peace of mind to leave agriculture, rural areas; can also migrant workers to urban employment to provide new sources of funding, so as to provide new impetus for new urbanization. Wang Xiaoqin compared China, the United States, Japan, France, Australia, Germany and other six countries on the three industries of the complete consumption coefficient of agriculture, the tertiary industry, the total consumption coefficient of the tertiary industry was only $7.92 \%$, while the OECD countries have reached $16 \%$, Is twice more than China, five typical developed countries, tertiary industry investment in agriculture is higher, Germany is as

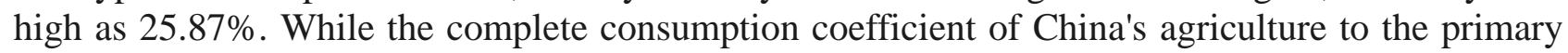
industry and the complete consumption coefficient of the secondary industry is not very different from the average level of the OECD countries. The results show that compared with the developed economies, China's agricultural production factor investment gap is mainly concentrated in the 
service industry investment in agriculture. Further analysis shows that the underlying cause of the lagging development of China's agricultural productive service industry is that agricultural development is lagging behind, so that the potential demand for agricultural productive service industry can not be transformed into realistic demand, leading to low contribution rate of agricultural productive service industry to agriculture, It can not effectively change the traditional agricultural production and management methods, and then the supply side of the structural problems, and this structural problems attributed to the agricultural land system and household registration system reform caused by a series of chain reaction.

\section{Other Studies}

Xiamen University famous economist Professor Xu Jingyong adheres to the market mechanism of agricultural supply side of the structural reform. Professor $\mathrm{Xu}$ believes that from the market regulation of supply and demand, the allocation of resources is distorted, there is an adverse supply from the market demand, structural supply surplus and structural supply shortage, agricultural supply side structural reform was timely. Advocating the practice of structural transformation of the manufacturing sector can not be rigidly applied to the agricultural sector; agricultural production and reproduction of the particularity of the decision to the production capacity is not suitable for agriculture; to promote the use of circulation channels as a test stone to measure the effectiveness of supply and agricultural production efficiency ; The core is to improve the total factor productivity in order to achieve the structural reform of the agricultural supply side to enhance the international competitiveness of China's agriculture; continuous reform is not conducive to play the market in the allocation of resources in the decisive role of the system, cultivate the rural factor market is conducive to backward areas of surplus labor And other resources in the developed areas to find a better opportunity to play for the backward regional economic development accumulation of capital, information and technical strength, so as to achieve the goal of narrowing the gap between rich and poor regions. Yang Jianli and so on, the agricultural supply side of the structural reform of the primary task is to protect the supply, the core content is to adjust the structure, the key link is to mention quality, an important measure is to promote integration. The author comprehensively analyzes the severe challenges of the structural reform of the agricultural supply side in China, such as the small scale of farmer operation, the weak agricultural infrastructure, the short supply of agricultural industry chain, the weak ability of agricultural science and technology support and the imperfect agricultural subsidy policy. Moderate scale operation, strengthen the construction of agricultural infrastructure, accelerate the deep integration of rural 123 industry, strengthen the modern agricultural science and technology innovation, improve the agricultural subsidy policy and other measures.

\section{Conclusion}

The existing literature on the structural reform of the agricultural supply side has emerged in the central government after the major deployment of the structural reform of the agricultural supply side. In the traditional agricultural economic research, the "agricultural industry structure optimization and upgrading", "the main agricultural cultivation", " Industrial integration "," agricultural brand development strategy "," rural land management system reform "and other aspects of the rich results, but the results of the induction shows that these studies pay more attention to the CPC Central Committee and State Council policy document theoretical research, Empirical analysis and classical case analysis, and can not provide useful reference for structural reform of agricultural supply side in different regions.

\section{References}

[1] Li Guoxiang. supply side reform and China's agricultural development transformation and upgrading, agricultural economy, 2016 (1) 
[2] Li Shipeng. Xinjiang agricultural industry structure adjustment optimization research, Xinjiang University outstanding master's degree thesis, 2012

[3] Yang Lei., the main task of rural financial supply side reform and focus analysis, rural economy, $2016(2)$

[4] Pan Kun. agricultural supply side of the reform of the farmers in the main thinking, social scientists, 2016 (6)

[5] Zhao Hai. rural one two three industry integration development, rural management, 2015 (7)

[6] Li Junling. China's multi-functional agricultural development research - based on industrial integration research; agricultural economy, 2009 (3)

[7] Zhang Yibo. agricultural modernization vision of industrial integration interaction and its path to find, reform, 2015 (2)

[8] Zhang Shoukui. one two three industrial integration development to promote the agricultural supply side of the structural reform path, theoretical guide, 2016 (5)

[9] Wang Xingguo. to promote the integration of rural economic development of the idea and policy research, Dong Yue, 2016 (2)

[10] Chen Wensheng. on the focus of structural reform of China's agricultural supply side - to adjust the agricultural structure, rural economy, 2016 (11) by regional landmark brand,

[11] Hu Xiaoyun. in-depth implementation of the agricultural brand strategy to truly realize the agricultural supply side reform, China cooperative economy, 2016 (3)

[12] Li Yan. agricultural supply side reform "one county one product" development strategy research, agricultural product quality and safety, 2017 (1)

[13] Li Sheng. to promote the supply of agricultural facilities in Jiangsu Province, the path of reform, Jiangsu Agricultural Sciences, 2016 (11)

[14] Guan Huiming. to build a new pattern of scientific and technological innovation to promote structural reform of agricultural supply side, China Rural Science and Technology, 2016 (5)

[15] Kong Xiangzhi. agricultural supply side of the structural reform of the basic connotation and policy recommendations, reform, 2016 (2)

[16] Wang Xiaoqin. from the perspective of industrial integration to explore the agricultural supply side of structural reform, business economics research, 2017 (6)

[17] Xu Jingyong. agricultural supply side of the structural reform of the deep thinking, learning forum, 2016 (6)

[18] Yang Jianli. China's agricultural supply side of the structural reform research, agricultural modernization research, 2016 (7) 